\title{
Computed Tomography Imaging Assessment of the Effect of Vancomycin Paste on Poststernotomy Healing
}

\author{
Mohammad Abd Alkhalik \\ Basha ${ }^{1}{ }^{\prime}$ \\ Dina Said Shemais ${ }^{2}$ \\ Essam Saad Abdelwahed ${ }^{2}$ \\ Rabab Mahmoud Elfwakhry' \\ Ayman Fathy Zeid' \\ Ahmed A El-Hamid M Abdalla' \\ Sameh Abdelaziz Aly ${ }^{3}$ \\ Dalia Said Abdelrahman ${ }^{3}$ \\ Anwar A Elshenawy ${ }^{4}$ \\ Waleed Mansour (ID ${ }^{5}$ \\ Khaled Ahmed Ahmed Elbanna ${ }^{6}$ \\ Mohammad El Tahlawi ${ }^{7}$ \\ Nezar Elnahal ${ }^{2}$ \\ 'Department of Radiodiagnosis, Faculty \\ of Human Medicine, Zagazig University, \\ Zagazig, Egypt; ${ }^{2}$ Department of \\ Cardiothoracic Surgery, Faculty of \\ Human Medicine, Zagazig University, \\ Zagazig, Egypt; ${ }^{3}$ Department of \\ Radiodiagnosis, Faculty of Human \\ Medicine, Benha University, Benha, Egypt; \\ ${ }^{4}$ Department of Surgical Oncology, \\ Faculty of Human Medicine, Aswan \\ University, Aswan, Egypt; ${ }^{5}$ Department of \\ Chest Medicine, Faculty of Human \\ Medicine, Zagazig University, Zagazig, \\ Egypt; ${ }^{6}$ Department of Internal Medicine, \\ Faculty of Human Medicine, Zagazig \\ University, Zagazig, Egypt; ${ }^{7}$ Department \\ of Cardiology, Faculty of Human \\ Medicine, Zagazig University, Zagazig, \\ Egypt
}

Correspondence: Mohammad Abd

Alkhalik Basha

Department of Radiodiagnosis, Faculty of

Human Medicine, Zagazig University,

Zagazig, 4463I, Egypt

Tel +20 1099098900

Email Mohammad_basha76@yahoo.com
Purpose: To assess vancomycin paste effect on poststernotomy healing in high-risk coronary artery bypass grafting $(\mathrm{CABG})$ patients compared to bone wax using the 6-point computed tomography (CT) score. Additionally assessed the reliability of this score and its relationship to the occurrence of infection.

Patients and Methods: A prospective comparative analysis included 126 high-risk CABG patients. The patients were randomly assigned into bone wax or vancomycin paste for sternal haemostasis. All patients were submitted to CT examinations 6-months postoperative. Two radiologists independently reviewed all $\mathrm{CT}$ scans to assess sternal healing using the 6-point CT score. The CT healing score of the two groups was compared. The kappa statistics were used to calculate the inter-reader agreement (IRA) of the 6-point CT score.

Results: The final analysis included 61 patients in each group. The main CT score for sternal healing was $3.9 \pm 0.4$ in the vancomycin group and $3.3 \pm 0.8$ in the bone wax group. Patients in the vancomycin group had a higher statistically significant improvement in CT healing score than those in the bone wax group $(p<0.001)$. There was no statistically significant relationship $(p=0.79)$ between the occurrence of infection and the 6-point CT score in the vancomycin group. The overall IRA of the 6-point CT score was good in two groups $(\kappa=$ 0.79 in the vancomycin group and $=0.78$ in the bone wax group).

Conclusion: Vancomycin paste had a better CT healing score and can be used as a sternal haemostatic material instead of bone wax. The 6-point CT healing score is a reliable diagnostic tool for evaluating sternal healing.

Keywords: computed tomography, sternal healing, poststernotomy, vancomycin paste, CT

\section{Introduction}

Sternal bone instability after median sternotomy is a predisposing factor for developing deep sternal wound infections and mediastinitis. Bleeding from the sternal wound is a major contributing factor for sternal and mediastinal infection leading to mortality and morbidity. ${ }^{1,2}$ Different materials were developed to effectively control the bleeding, including cement and paste, but did not receive a wider application. Bone wax is a commonly used material for haemostasis, but it has been associated with impaired sternal healing, infection, and chronic inflammatory reactions. ${ }^{3-5}$ Vancomycin paste is comparably cheap, easily prepared and applied, and shows no significant side effects. It is a bactericidal and bacteriostatic agent for gram-positive bacteria. It can replace the bone wax application. $^{6}$ 
The evaluation of sternal bone instability depends on palpation, a straightforward technique often used in clinical practice. ${ }^{7}$ However, this form of assessment is subjective and vulnerable to misinterpretations. Computed tomography (CT) is currently the most valuable and insightful imaging tool for evaluating sternotomy healing. It can show gaps and steel wire displacement. ${ }^{8}$ Few previous studies have been performed to assess sternal healing using $\mathrm{CT}^{4,9}$ Recently, Stacy et al developed a simple scoring algorithm for evaluating sternal bone healing after sternotomy using the basic CT imaging features of the various sternal healing patterns. This score comprised a 6-point scale ranging from non-union (Score 0) to complete healing (Score 5). ${ }^{10}$

Strict following of the guidelines will reduce postoperative infections and complications and improve survival. Particularly in patients infected with COVID-19, bone wax should be avoided [class III] and replaced by vancomycin paste in all heart surgeries [class I] ${ }^{11}$ Therefore, we conducted this prospective study using the 6-point CT score of sternal healing to assess the effect of vancomycin paste on poststernotomy healing in high-risk coronary artery bypass grafting (CABG) patients compared to bone wax. Additionally assessed the reliability of this score and its relationship to the occurrence of infection.

\section{Materials and Methods}

\section{Ethical Statement}

The institutional review board of Zagazig University approved the study (approval number, 5247-23-2-2019; Date, February 23, 2019), and written informed consent was taken from all patients involved in the study. The study was conducted according to the ethical principles of the declaration of Helsinki.

\section{Study Design and Population}

The study was carried out in a tertiary health institution between March 2019 and February 2021. Initially, 156 CABG patients were screened for the study; they were categorized as high-risk patients for poststernotomy wound complications. Inclusion criteria were: 1) adult patients with $\mathrm{CABG}$ surgery; 2) patients operated through median sternotomy with the harvesting of the left internal thoracic artery (LITA); 3) on-pump open heart surgery; and 4) patients at high risk for postoperative sternal complications, e.g., old age $>60$ years, diabetes mellitus, obesity (BMI $>30 \mathrm{Kg} / \mathrm{m} 2$ ), osteoporosis of the sternum, chronic obstructive pulmonary disease (COPD), steroid therapy or immunosuppression, intraoperative intra-aortic balloon pump (IABP) use, re-exploration for bleeding, long time of cardiopulmonary bypass time (CBP) (>180 minutes). Exclusion criteria are detailed in Figure 1. The exclusion process resulted in a final cohort consisting of 126 patients. There were no patients of bilateral ITA harvest, and no patients had immunosuppressed status or a diagnosis of osteoporosis. All patients had not smoked for at least one year. Our patients were randomized to either bone wax or vancomycin groups by one of the authors using serially numbered containers. Vancomycin group $(n=62)$, patients in this group had local sternal vancomycin paste for sternotomy haemostasis. Preparation of vancomycin paste was as follows: 2.5 gm of powdered vancomycin was mixed with $3 \mathrm{~mL}$ of normal saline and stirred until a paste was formed. It was applied to both sternal halves, similar to bone wax, if significant bleeding spots from the bone marrow after sternotomy. Also, It was used for sternal haemostasis in all patients in the vancomycin group just before sternal wiring. Bone wax was not used for haemostasis at any step of the operation. The sternum was closed by eight simple steel wires. A figure of eight wires was added as judged by the surgeon. Reinforced sternal closure with Robicsek technique in each half of the divided sternum, in addition to simple sternal wires in cases with thin sternum. Bone wax group $(\mathrm{n}=64)$, patients in this group received sternal wires as mentioned above in the vancomycin group. Bone wax was used for haemostasis on the divided edge of the sternum for haemostasis. The author used SPSS version 20.0 to generate the random allocation sequence. Randomization was done in blocks of two, four, and six. To implement the random allocation process, the author randomized the consecutively numbered containers filled with vancomycin paste and bone wax in a location removed from the operative room and inaccessible to the surgeons. Each container was identical in size, shape, and weight. The numbered containers were held in the operation pharmacy and delivered sequentially to surgeons at operation time. Our analysts were not the same surgeons who performed the operations, and they analyzed the data set blinded to group assignment.

\section{Surgical Technique}

Two surgeons (N.E and E.S.A, with over 10 years of experience in cardiothoracic surgery) operated all patients. N.E operated 33 patients in the vancomycin group and 34 


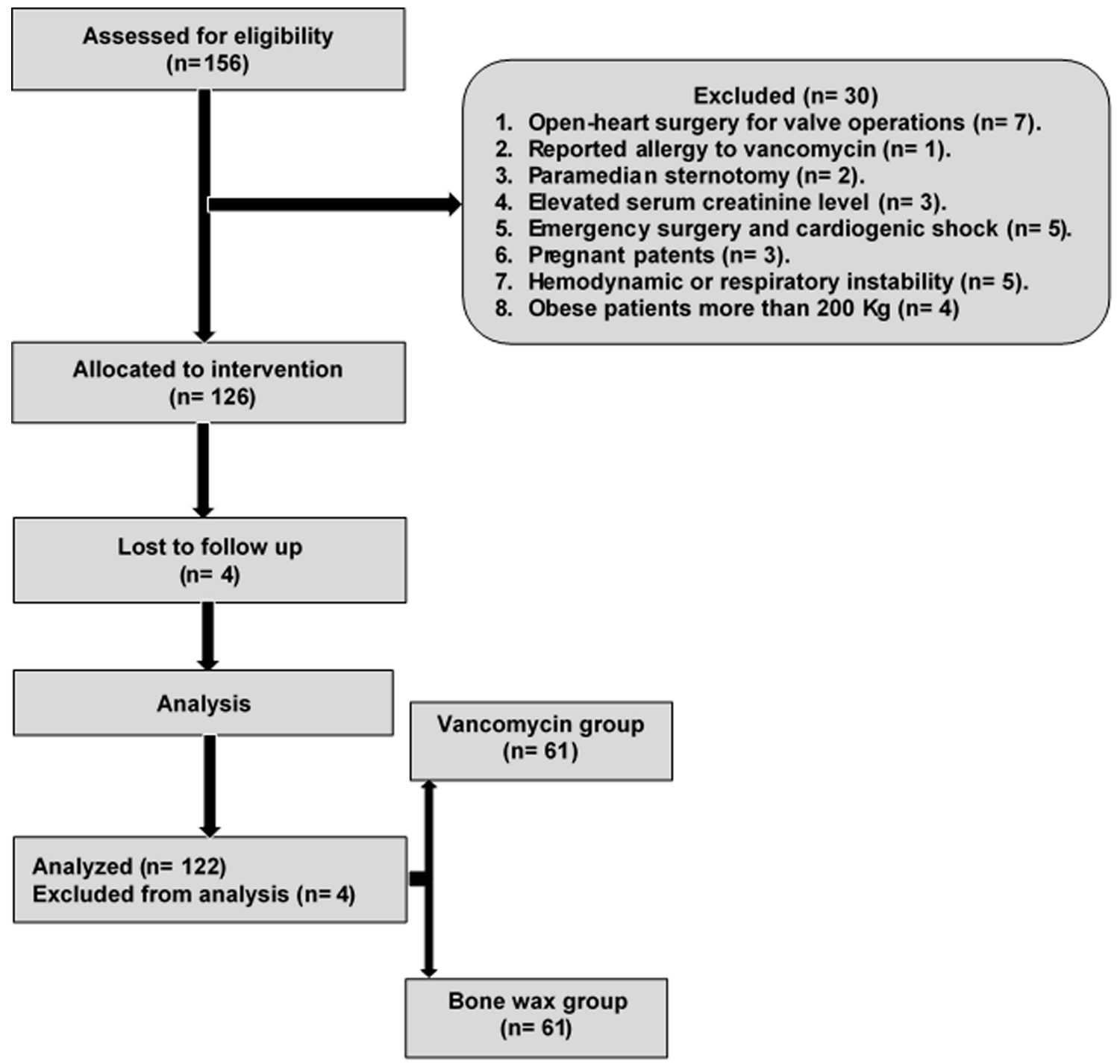

Figure I Flow chart of the study.

patients in the bone wax group. E.S.A operated 29 patients in the vancomycin group and 30 patients in the bone wax group. All operations were performed under standard general cardiac anaesthesia through a median sternotomy. Immediately after median sternotomy, electrocautery was enough to control bleeding from the periosteum in all cases. Bleeding from the bone marrow was controlled by applying a sterile towel on each cut sternal edges under the sternal retractor. Initially, the left internal thoracic artery was harvested in all patients. Simultaneously, venous grafts were obtained by harvesting the great saphenous vein if indicated for other targets. Standard cannulation for CBP. All procedures were performed on heparinbonded CBP circuits with a membrane oxygenator. Cardiac arrest was achieved by antegrade blood cardioplegia. LITA was anastomosed as a pedicle graft to the diseased left anterior descending lesion artery. Venous grafts were anastomosed to other indicated diseased coronary arteries depending on each case. The muscle, fascia, and subcutaneous layer were closed carefully in an anatomical fashion with the standard technique. Finally, the skin layer was closed with running, monofilament absorbable sutures. Then all patients were transferred to our postcardiac surgery intensive care unit on mechanical ventilation and inotropic support or other drug infusions (s) if needed.

\section{Postoperative Follow-Up}

Early postoperative follow-up in-hospital stay included clinical examination of the poststernotomy wound, routine 
laboratory investigations, and follow-up plain chest X-ray. Follow-up kidney function tests were performed for the patients in the vancomycin group. Patients in the vancomycin group were followed up for allergy, rash, renal, and hearing problems. Late postoperative follow-up included routine full clinical evaluation of the patients with special focusing on sternotomy wound healing progress and presence of any criteria of wound infection through clinical and laboratory data. Frequent analysis was done to detect the presence of markers of sternotomy wound infection in the form of leucocytosis, elevated C-reactive protein (CRP), elevated erythrocyte sedimentation rate (ESR) and elevated serum procalcitonin level. A swab from the discharge or infected wound was taken to detect the causative organism and apply appropriate antibiotics. Measurement of procalcitonin level if there were any clinical signs or symptoms of sternotomy wound infection. CT examination of the chest without contrast was done for evaluation of sternal healing.

\section{Antibiotic Prophylaxis}

Within 60 minutes before the skin incision, $50 \mathrm{mg} / \mathrm{kg}$ cefepime was given for the patients as an intravenous infusion over 30 minutes. A second dose of $1 \mathrm{gm}$ cefepime was given if the surgical incision remained open for more than 3-4 hours. Two gm of cefepime were used daily for 48 hours postoperatively for prophylaxis against poststernotomy infections.

\section{CT Examination}

All CT examinations were performed 6-months postoperative using 128-multidetector computed tomography (MDCT) scanner (Philips ingenuity 128). The following parameters were used: detector row configuration, $128 \times$ $1 \mathrm{~mm}$; collimation, $1 \mathrm{~mm}$; slice thickness, $1.25 \mathrm{~mm}$; pitch, 1.375; reconstruction interval, $1 \mathrm{~mm} ; 300 \mathrm{mAs}$; and 120 Kv. No specific patient preparation was required apart from quiet breathing. Patients were scanned in a supine position with the head first without gantry tilt. The scan started below the diaphragm and ended at supraclavicular regions. Bone window (window level, $300 \mathrm{HU}$; window width, $1500 \mathrm{HU}$ ) was specified to evaluate the sternal healing.

\section{Image Interpretation}

All CT images were moved to the workstations, and image processing and interpretation were carried out on the picture archiving and communication system (PACS)
(PaxeraUltima-paxeramed), or a dedicated platform Extended Brilliance Workstation (Philips Medical System, Best, The Netherlands). Multiplanar reconstruction (MPR) was obtained using the machine software in sagittal and coronal planes. The thin axial slices were used to reconstruct 3D images. Two radiologists (A.Z and R.E with over five years of experience in cardiac imaging) independently reviewed all CT images. The radiologists were blinded to any clinical data and patients' group but used the 6-point CT score developed by Stacy et al (Table 1$)^{10,12,13}$ to detect the degree of sternal healing. Before the study began, each radiologist received several clinical sessions of lecture-based on the details of the 6-point CT score in addition to hands-on instruction sessions with some practical cases that were not part of the study community. The axial source images (bone window) and post-processing images of each patient were reviewed for the following features: gap mineralization between the sternal halves, sternal approximation and alignment, and imaging characteristics of the osteotomy margins (i.e., contour irregularity, absence or presence of sclerosis, or resorption). ${ }^{10}$ Five anatomic levels (Table 2) are used to assess healing over the whole length of the sternum. If an accurate scoring was difficult at the original level due to a streak artifact from wires or sternal plates, a level within two cuts of the original level could be chosen for scoring. ${ }^{10}$ Finally, each radiologist independently assigned a sternal healing score for each patient using the 6-point CT score. ${ }^{10,12,13}$ The score was calculated at each level, and then the overall score and mean were calculated. The inter-reader agreement (IRA) was first determined between two independent radiologists regarding the overall CT score of each patient. In cases of disagreement on the score between the two radiologists, images were re-reviewed together, and a consensus scoring was achieved.

\section{Statistical Analysis}

Microsoft Excel was used to code, enter, and interpret the data. The data was then analyzed using the SPSS version 20.0. The Chi-square test was applied to compare between two groups. The correlation was done by the Pearson correlation test. The IRA of 6-point CT score was calculated using kappa statistics. The resulting $\kappa$ values were interpreted as follows: poor agreement $=0.00-0.20$; fair agreement $=0.21-0.40 ;$ moderate agreement $=0.41-0.60$; good agreement $=0.61-0.80$; and very good agreement $=$ 0.81-1.00. P-value was set at $<0.05$ for significant results. 
Table I Parameters of 6-Point Scale to Evaluate Sternal Bone Healing

\begin{tabular}{|l|l|l|}
\hline Score & Definition & Description \\
\hline 0 & $\begin{array}{l}\text { No signs of healing (non- } \\
\text { union) }\end{array}$ & $\begin{array}{l}\text { No contact between sternal halves, absence of gap mineralization, and sclerotic osteotomy margins } \\
\text { similar to that of cortical bone }\end{array}$ \\
\hline $\mathbf{I}$ & Indeterminate & $\begin{array}{l}\text { No contact or mineralization between the sternal halves, but osteotomy margins were nonsclerotic, } \\
\text { concave, or irregular }\end{array}$ \\
\hline 2 & $\begin{array}{l}\text { Signs suggesting minimal or } \\
\text { early healing }\end{array}$ & $\begin{array}{l}\text { Faint mineralization between non-contacting sternal halves, a thin (I mm) bridge of bone connecting the } \\
\text { sternal halves anteriorly or posteriorly, or near bone-on-bone contact between the sternal halves, with } \\
\text { sclerotic osteotomy margins }\end{array}$ \\
\hline 3 & Mild synthesis & $\begin{array}{l}\text { Bridging bone (i.e., no perceptible gap) along with less than } 50 \% \text { of the anteroposterior dimension of the } \\
\text { sternal halves, with the sternal halves either offset in the anteroposterior dimension or aligned in the } \\
\text { anteroposterior dimension }\end{array}$ \\
\hline 4 & Moderate synthesis & $\begin{array}{l}\text { Bridging bone (i.e., no perceptible gap) along } 50 \% \text { or more of the anteroposterior dimension of the } \\
\text { sternal halves, with the sternal halves either offset in the anteroposterior dimension or aligned in the } \\
\text { anteroposterior dimension, with visible remnants of the previous osteotomy }\end{array}$ \\
\hline 5 & Complete synthesis & $\begin{array}{l}\text { Sternal halves were well-aligned, and the appearance was that of essentially normal bone, without a gap or } \\
\text { visible osteotomy margin }\end{array}$ \\
\hline
\end{tabular}

Notes: Adapted from: Stacy GS, Ahmed O, Richardson A, Hatcher BM, MacMahon H, Raman J. Evaluation of sternal bone healing with computed tomography and a quantitative scoring algorithm. Open Med Imaging J 2014;8;29-35. doi:10.2174/1874347/01408010029. ${ }^{10}$ ๑ Stacy et al; Licensee Bentham Open. Creative Commons Attribution Non-Commercial License (http://creativecommons.org/licenses/bync/3.0/).

Table 2 Sternal Levels Used for Assessment of Sternal Bone Healing by 6-Point Scale

\begin{tabular}{|l|l|}
\hline Level & Description \\
\hline Level I & Manubrium at the first sternocostal articulation, using the first slice that does not show the clavicles (scrolling from cranial to caudal) \\
\hline Level 2 & $\begin{array}{l}\text { Upper end of sternal body, using first slice below the second costal cartilage that does not show the sternomanubrial junction (scrolling } \\
\text { from cranial to caudal) }\end{array}$ \\
\hline Level 3 & Mid-upper sternal body, using the slice through the lowest margin of the third costal cartilage \\
\hline Level 4 & Mid-lower sternal body, using the slice through the lowest margin of the fourth costal cartilage \\
\hline Level 5 & $\begin{array}{l}\text { Lower end of sternal body, using the first slice at the level of the fifth costal cartilage that does not show the xiphoid process or xiphoid- } \\
\text { body junction (scrolling from caudal to cranial) }\end{array}$ \\
\hline
\end{tabular}

Notes: Adapted from: Stacy GS, Ahmed O, Richardson A, Hatcher BM, MacMahon H, Raman J. Evaluation of sternal bone healing with computed tomography and a quantitative scoring algorithm. Open Med Imaging J 2014;8;29-35. doi: 10.2174/1874347/01408010029. ${ }^{10}$ Creative Commons Attribution Non-Commercial License (http:// creativecommons.org/licenses/bync/3.0/).

\section{Results}

\section{Patient Characteristics}

This study initially enrolled 126 patients. Of these 126 patients, four were lost to follow-up (one in the vancomycin group and three in the bone wax group) and excluded from the final analysis. Hence, the final analysis included 122 patients. The flow chart of our study is illustrated in Figure 1. The general characteristics of the studied patients are described in Table 3. No significant difference $(p>$ 0.05 ) was observed between the two groups regarding age, sex, and risk factors.

\section{Perioperative Data}

The perioperative data are illustrated in Table 4 . There was no significant difference $(p>0.05)$ between the two groups regarding perioperative data.

\section{Poststernotomy Wound Infection}

Figure 2 shows the prevalence of poststernotomy wound infection. We noted a statistically significant increase $(p=0.006)$ in the prevalence of superficial sternotomy infection among patients in the bone wax group compared to vancomycin group patients. In two groups, patients with superficial serous 
Table 3 General Characteristics of the Studied Patients

\begin{tabular}{|l|c|c|c|}
\hline Variables & Vancomycin Group (n= 6I) & Bone Wax Group (n= 6I) & P-value \\
\hline Age, years & $57.3 \pm 5.5(45-67)$ & $58 \pm 5.1(48-67)$ & 0.15 \\
\hline Sex, $\mathrm{n}(\%)$ & & & 0.84 \\
Male & $45(73.8)$ & $46(75.4)$ & \\
Female & $16(26.2)$ & $15(24.6)$ & \\
\hline Risk factors & & $35.2 \pm 2.2(30.1-38)$ & 0.24 \\
BMl & $35.8 \pm 2.5(30.2-39)$ & $7.9 \pm 0.5(7.2-8.5)$ & 0.27 \\
HbAIC & $7.8 \pm 0.5(7-8.6)$ & $9(14.8)$ & 0.80 \\
COPD, n (\%) & $10(16.4)$ & \\
\hline
\end{tabular}

Notes: Unless otherwise indicated, data represent the mean \pm SD and range in parenthesis.

Abbreviations: SD, standard deviation; BMI, body mass index; HBAIC, haemoglobin AIC; COPD, chronic obstructive pulmonary disease.

Table 4 Perioperative Data in the Two Groups

\begin{tabular}{|c|c|c|c|}
\hline & Vancomycin Group $(n=61)$ & Bone Wax Group $(n=61)$ & P-value \\
\hline Ischemic time (minutes) & $56.6 \pm 14.3(20-80)$ & $59.7 \pm 14.7(20-90)$ & 0.25 \\
\hline CBP time (minutes) & $94.1 \pm 24.7(45-150)$ & $100.7 \pm 27.3(45-160)$ & 0.16 \\
\hline Number of grafts & $2.9 \pm 0.6(I-4)$ & $3 \pm 0.7(I-4)$ & 0.89 \\
\hline Total operation time (minutes) & $190 \pm 34.7(135-300)$ & $205 \pm 39.1(135-300)$ & 0.16 \\
\hline IABP use, n (\%) & I (I.6) & I (I.6) & 1.0 \\
\hline Re-exploration for bleeding, n (\%) & $5(8.2)$ & $4(6.6)$ & 0.52 \\
\hline Mechanical ventilation period hours & $7 \pm 9.4(3-72)$ & $6.2 \pm 5.4(3-36)$ & 0.82 \\
\hline Blood transfusion units (Packed RBCs) & $2.9 \pm 1.3(I-8)$ & $2.8 \pm 1.3(I-8)$ & 0.68 \\
\hline Total tube drainage $/ \mathrm{mL}$ & $418.9 \pm 263.97(200-1500)$ & $412.4 \pm 224.8(200-1200)$ & 0.77 \\
\hline Vasopressor duration (days) & $1.3 \pm 0.7(I-5)$ & $1.2 \pm 0.5(I-3)$ & 0.61 \\
\hline Postoperative ICU stay (days) & $2.5 \pm 1(2-7)$ & $2.3 \pm 0.7(2-4)$ & 0.47 \\
\hline Total hospitalization period & $11 \pm 3.6(8-26)$ & $10.3 \pm 2.3(8-18)$ & 0.23 \\
\hline
\end{tabular}

Notes: Unless otherwise indicated, data represent the main \pm standard deviation and range in parenthesis.

Abbreviations: CBP, cardiopulmonary bypass time; IABP, Intra-Aortic Balloon Pump; RBCs, red blood cells; ICU, intensive care unit.

discharge were improved with frequent sterile wound dressing once or twice daily as required according to the amount of discharge in every patient. Patients in two groups who had early sternal rocking detected at discharge time in two groups had a follow-up of the wound and thoracic support vest. In the bone wax group, the seven patients with infected purulent discharge had frequent sterile dressing twice daily. The two patients who had late sternal dehiscence with deep mediastinitis were submitted to exploration, debridement of infected tissues, rewiring with reinforced sternal closure and mediastinal wash with vancomycin and cefotaxime till lavage is clear.

\section{Six-Point CT Healing Score}

Assignment of the 6-point CT score for sternal healing in the two groups stratified by readers is shown in Table 5 . The majority of the patients in the vancomycin group had better sternal healing (score 4) than those in the bone wax group (86.9\% vs. 52.5\%). The main CT score for sternal healing was $3.9 \pm 0.4$ (range $=3-5$ ) in the vancomycin group and $3.3 \pm 0.8$ (range $=2-4$ ) in the bone wax group. There was a high statistically significant improvement ( $p$ $<0.001)$ in CT healing scores among patients in the vancomycin group than in the bone wax group.

We found a statistically significant relationship ( $p=$ 0.003 ) between the occurrence of infection and the 6-point CT score in the bone wax group. In contrast, there was no statistically significant relationship $(p=0.79)$ between the occurrence of infection and the 6-point CT score in the vancomycin group (Table 6).

\section{Reproducibility of 6-Point CT Healing Score}

The overall IRA of the 6-point CT score was good in two groups $(\kappa=0.79,95 \% \mathrm{CI}: 0.66-0.93$ in vancomycin group and $\kappa=0.78,95 \% \mathrm{CI}: 0.68-0.88$ in the bone wax group). 


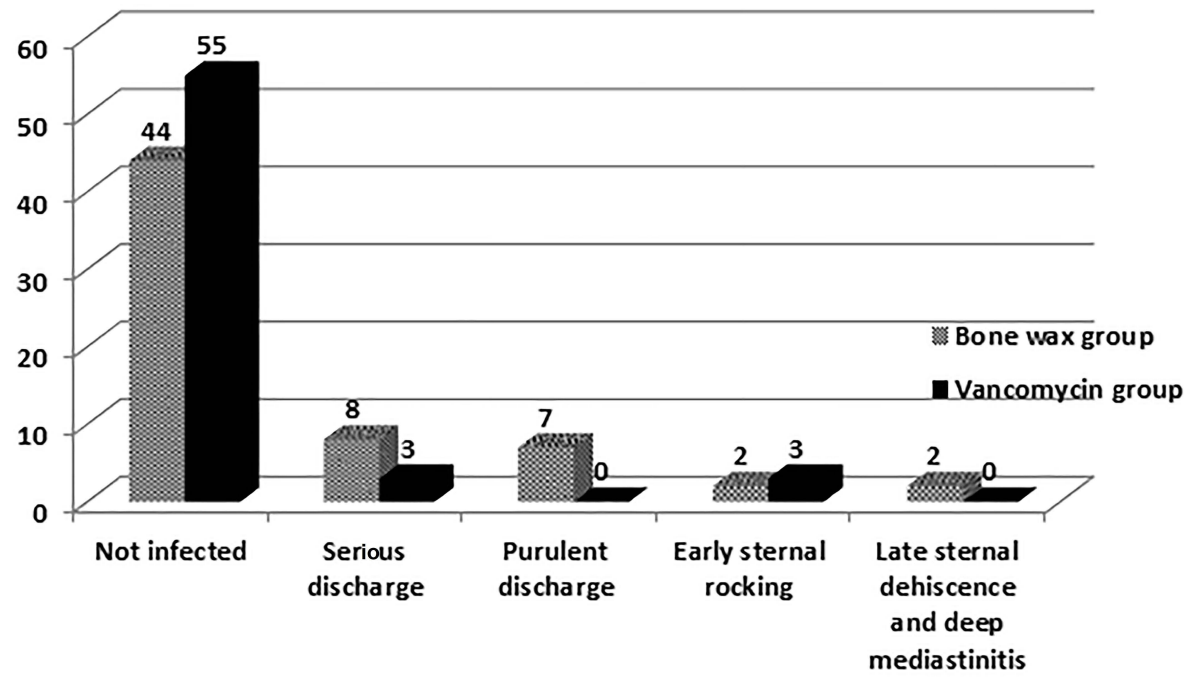

Figure 2 Bar chart shows the poststernotomy wound infection in both groups.

Representative cases of our study are shown in Figures 3 and 4.

\section{Discussion}

The main objective of any material used for sternal haemostasis is to be safe and effective. This study radiologically investigated the impact of two haemostatic materials on sternal bone healing in high-risk CABG patients - the vancomycin paste and the bone wax. Although the safety and efficacy of these materials have been investigated, ${ }^{4,14,15}$ up to date, the imaging comparison between the effect of vancomycin paste and bone wax on sternal healing has not been tested. The present study prospectively compared the 6-point CT score of sternal healing of vancomycin paste to that of bone wax.

In comparing vancomycin paste to bone wax, our study found a highly statistically significant improvement ( $p$ $<0.001$ ) in CT healing score among patients of the vancomycin group, reflecting better sternal bone healing with vancomycin paste in comparison to bone wax. These findings support the previous literature, ${ }^{16-18}$ which recommends using local vancomycin paste in patients with comorbidities like diabetes mellitus and morbidly obese patients. However, these studies did not use imaging in the assessment of sternal healing.

Interestingly, a statistically significant relationship was found between the occurrence of infection and the 6-point CT score in the bone wax group ( $p=0.003)$. In contrast, no statistically significant relationship was found between the occurrence of infection and the 6-point $\mathrm{CT}$ score in the vancomycin group $(p=0.79)$. Moreover, patients with sternal rocking in the vancomycin group did not show a progression of infection. They also showed better healing scores than patients with early sternal rocking in the bone wax group. This supports the point that vancomycin paste prevents poststernotomy infection and offers better sternal

Table 5 Assignment of 6-Point CT Score for Sternal Healing in the Two Groups Stratified by Readers

\begin{tabular}{|c|c|c|c|c|c|c|}
\hline \multirow[t]{2}{*}{ Score } & \multicolumn{3}{|c|}{ Vancomycin Group $(n=61)$} & \multicolumn{3}{|c|}{ Bone Wax Group $(n=61)$} \\
\hline & Reader I & Reader 2 & Consensus & Reader I & Reader 2 & Consensus \\
\hline 0 & I (I.6) & 0 & 0 & $2(3.3)$ & I (I.6) & 0 \\
\hline 1 & 0 & $2(3.3)$ & 0 & $3(4.9)$ & $\mathrm{I}(\mathrm{I} .6)$ & 0 \\
\hline 2 & $2(3.3)$ & I (I.6) & 0 & $13(21.3)$ & $12(19.7)$ & $12(19.7)$ \\
\hline 3 & $4(6.6)$ & $8(13.1)$ & $6(9.8)$ & $19(3 \mid .2)$ & $17(27.8)$ & $17(27.8)$ \\
\hline 4 & $52(85.2)$ & $48(78.7)$ & $53(86.9)$ & $24(39.3)$ & $30(49.1)$ & $32(52.5)$ \\
\hline 5 & $2(3.3)$ & $2(3.3)$ & $2(3.3)$ & 0 & 0 & 0 \\
\hline Mean $\pm \mathrm{SD}$ (range) & $3.8 \pm 0.7(0-5)$ & $3.8 \pm 0.7(I-5)$ & $3.9 \pm 0.4(3-5)$ & $3 \pm 1.1(0-4)$ & $3.2 \pm 0.9(0-4)$ & $3.3 \pm 0.8(2-4)$ \\
\hline
\end{tabular}

Notes: Unless otherwise indicated, data represent the number of patients and percentage in parenthesis. Abbreviation: SD, standard deviation. 
Table 6 Relation Between the Occurrence of Infection and 6-Point CT Score for Sternal Healing Among Patients of the Two Groups

\begin{tabular}{|l|c|c|c|}
\hline \multirow{2}{*}{} & \multicolumn{2}{|c|}{ P-value } \\
\cline { 2 - 4 } & Infected Patient & Non-Infected Patient \\
\hline Vancomycin group & $4 \pm 0.6(3-5)$ & $3.9 \pm 0.3(3-5)$ & 0.79 \\
Bone wax group & $3.2 \pm 0.6(2-4)$ & $3.8 \pm 0.5(3-4)$ & 0.003 \\
\hline
\end{tabular}

Notes: Data represent the main \pm standard deviation and range in parenthesis.

healing even in patients with postoperative superficial wound complications. ${ }^{14,19}$ In contrast, Lander et $\mathrm{al}^{20}$ reported that the application of vancomycin paste to the sternal edges of patients undergoing cardiac surgery was not associated with a reduced risk of deep sternal wound infection. However, it was a single-centre, retrospective study with limited data about systemic perioperative antibiotics administration. Furthermore, not all surgeons in this study used vancomycin paste, and there were changes in practice during the study period. These limitations may significantly impact the findings of this study.

To evaluate the safety of local sternal vancomycin paste on the kidney, we made follow-up kidney function tests of the patients in the vancomycin group. In our study, we did not find a significant increase in kidney function tests with its use. Desmond et $\mathrm{al}^{21}$ found that after topical sternal vancomycin use, vancomycin shows a significant therapeutic systemic level six hours post-surgery, but it does not persistently elevate serum vancomycin levels. It may be measured in urine for up to 5 days after surgery. However, Lazar et $\mathrm{al}^{22}$ demonstrated that vancomycin paste does not affect serum vancomycin levels or renal function.

Our results showed an overall good IRA of the 6-point CT score regardless of whether vancomycin paste or bone wax was used as a haemostatic material for sternal healing ( $\kappa=0.79$, and 0.78 , respectively). This result is consistent with Stacy et al, ${ }^{10}$ which reported that the 6-point CT score

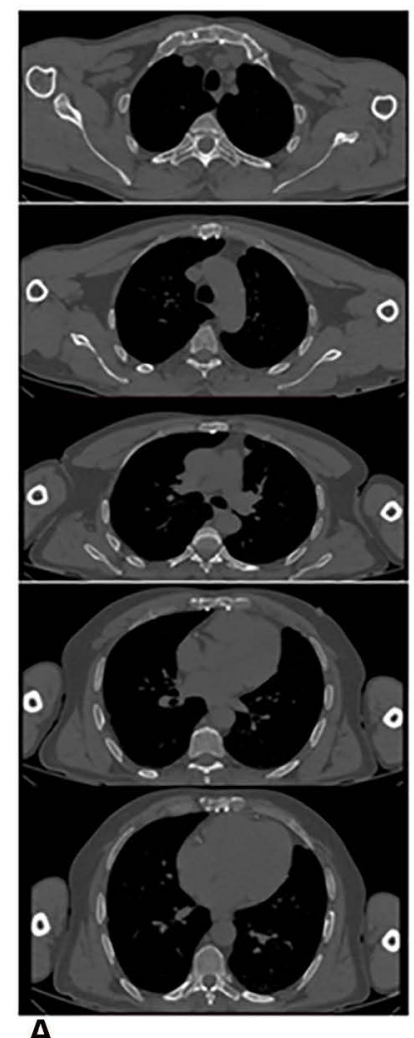

A

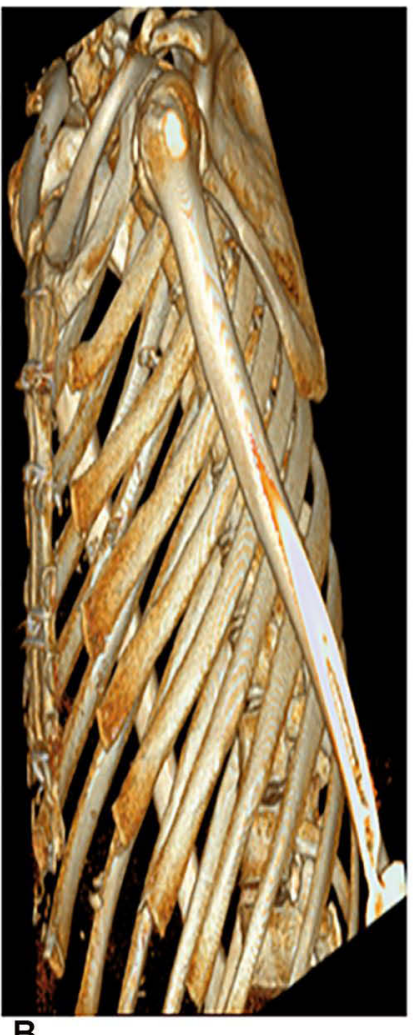

B

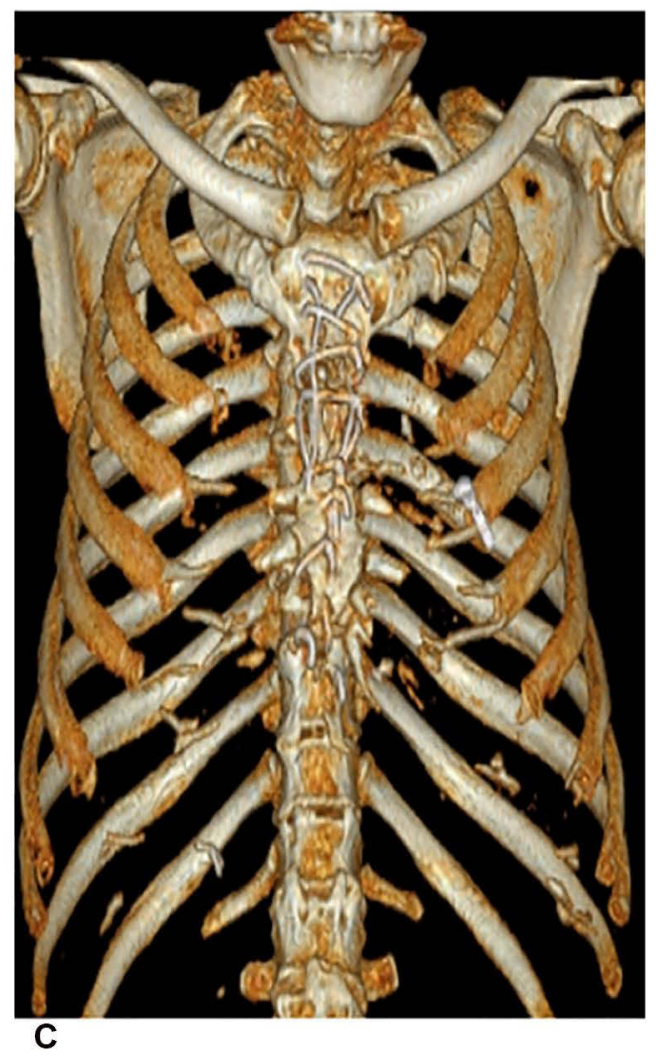

Figure 3 A 60-year-old-diabetic-male patient with sternotomy and received local sternal vancomycin paste. (A) Axial (bone window) images at the five fixed anatomic levels show the sternal halves are well-aligned. The appearance is that of essentially normal bone without gap or obvious osteotomy margin at all five levels. The mean 6-point CT score of sternal healing is 5, denoting complete healing. (B and C) A reformatted 3D image confirms the complete healing. 

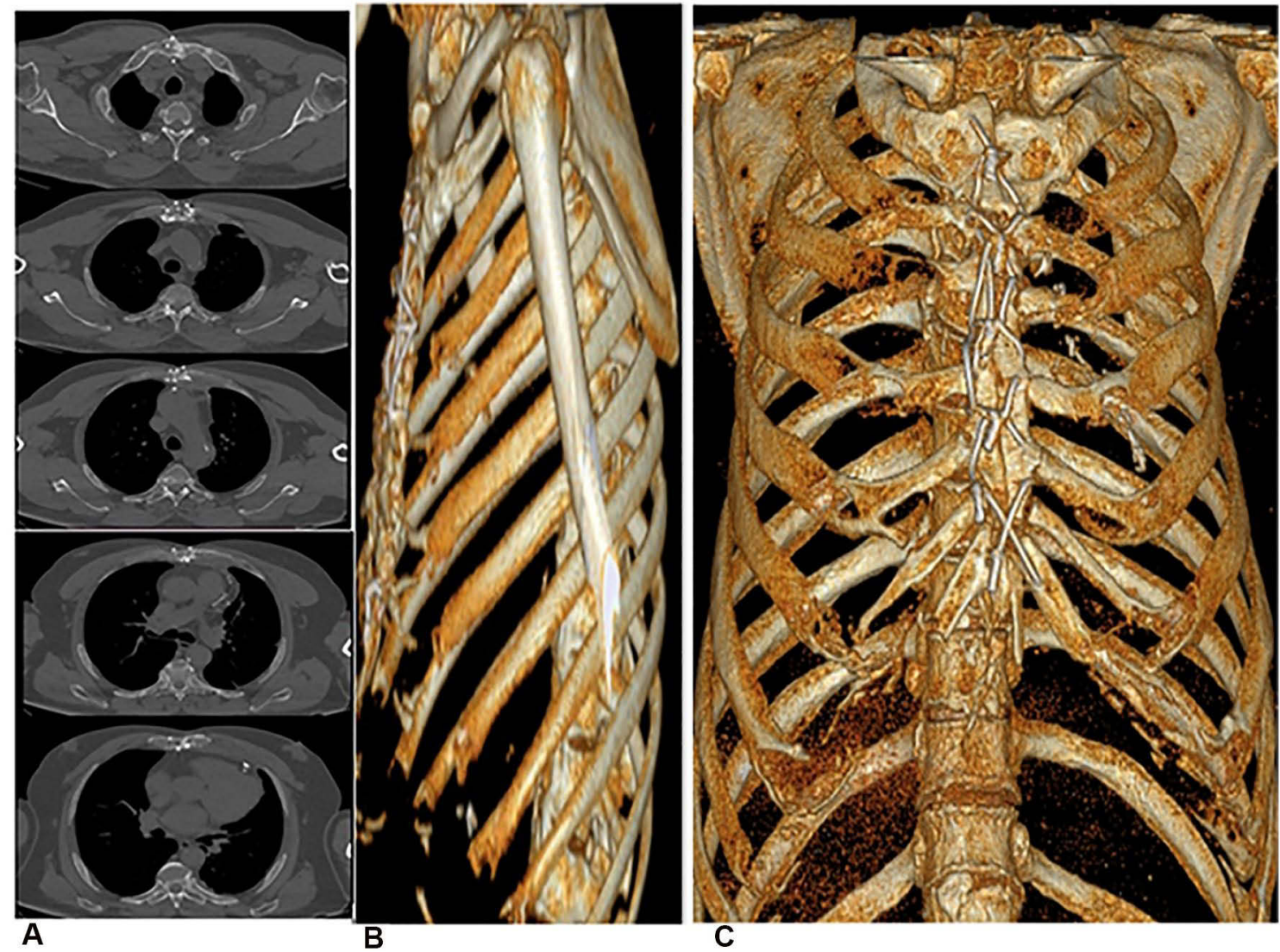

Figure 4 A 62-year-old-diabetic-male patient with sternotomy and received bone wax on the divided edge of the sternum. (A) Axial (bone window) images at the five fixed anatomic levels show level I, partial synthesis (significant bridging bone) (score 4). Level 2, no sign of healing (sternal separation, non-union, clear lack of healing) (score 0). Level 3, minimal healing (lack of bridging bone, sternal separation) (score I). Level 4, moderate healing (partial bridging bone) (score 3). Level 5, complete synthesis (complete bridging bone) (score 5). The mean CT score of sternal healing is 2.6, denoting incomplete healing. (B and C) A reformatted 3D image confirms the incomplete healing.

of sternal healing has moderate to substantial agreement for inter-observer reliability.

Finally, this study expands the literature by offering an insight into the promising potential of vancomycin paste in improving sternal healing in high-risk CABG patients and confirms the high reproducibility of the 6-point CT score in evaluating sternal healing after sternotomy. Moreover, establishes the basis for future studies to evaluate the value of a 6-point CT score in assessing sternal healing. Nevertheless, the current study had some limitations. First, the small size of study population. Second, the duration of the follow-up is short. Third, the CT imaging data were collected only six-months postoperative, rather than using multiple records: three, six, and 12 months. However, Vestergaard et $\mathrm{al}^{23}$ concluded that $\mathrm{CT}$ could not be used in the diagnostic criteria for sternal instability up to six months postoperatively. Fourth, the lack of reference standard with which we can compare the images. Despite these limitations, the study findings illustrate the imaging effects of vancomycin paste on improving sternal healing.

\section{Conclusions}

Vancomycin paste had a better CT healing score and can be used as a sternal haemostatic material instead of bone wax. The 6-point CT healing score is a reliable diagnostic tool for evaluating sternal healing after sternotomy in high-risk $\mathrm{CABG}$ patients.

\section{Ethical Approval}

Institutional review board approval was obtained.

\section{Informed Consent}

Written informed consent was obtained from all patients.

\section{Acknowledgment}

The authors thank all staff members and colleagues in the Radiology and Cardiothoracic Surgery Departments, 
Zagazig University, for their helpful cooperation. Regarding statistics and biometry: the authors report that the corresponding author has great statistical expertise.

\section{Funding}

The authors state that this work has not received any funding.

\section{Disclosure}

The authors declared no relevant conflicts of interest for this work.

\section{References}

1. Fynn-Thompson F, Vander Salm TJ. Methods for reduction of sternal wound infection. Semin Thorac Cardiovasc Surg. 2004;16(1):77-80. doi:10.1053/j.semtcvs.2004.01.004

2. Song DH, Lohman RF, Renucci JD, Jeevanandam V, Raman J. Primary sternal plating in high-risk patients prevents mediastinitis. Eur J Cardio-Thoracic Surg. 2004;26(2):367-372.

3. Lazar HL, Salm TV, Engelman R, Orgill D, Gordon S. Prevention and management of sternal wound infections. $J$ Thorac Cardiovasc Surg. 2016;152(4):962-972.

4. Vestergaard RF, Jensen H, Vind-Kezunovic S, Jakobsen T, Søballe K, Hasenkam JM. Bone healing after median sternotomy: a comparison of two hemostatic devices. J Cardiothorac Surg. 2010;5(1):1-8.

5. Ragusa R, Faggian G, Rungatscher A, Cugola D, Marcon A, Mazzucco A. Use of gelatin powder added to rifamycin versus bone wax in sternal wound hemostasis after cardiac surgery. Interact Cardiovasc Thorac Surg. 2007;6(1):52-55.

6. Lazar HL. Vancomycin paste and sternal wound infections. Ann Thorac Surg. 2018;105(1):335-336.

7. Francel TJ. A rational approach to sternal wound complications. Semin Thorac Cardiovasc Surg. 2004;16(1):81-91.

8. Restrepo CS, Martinez S, Lemos DF, et al. Imaging appearances of the sternum and sternoclavicular joints. Radiographic. 2009;29 (3):839-859.

9. Raman J, Lehmann S, Zehr K, et al. Sternal closure with rigid plate fixation versus wire closure: a randomized controlled multicenter trial. Ann Thorac Surg. 2012;94(6):1854-1861.

10. Stacy GS, Ahmed O, Richardson A, Hatcher BM, MacMahon H, Raman J. Evaluation of sternal bone healing with computed tomography and a quantitative scoring algorithm. Open Med Imaging J. 2014;8:29-35. doi:10.2174/1874347101408010029
11. Lazar HL. Commentary: compliance with the American Association for Thoracic Surgery guidelines will prevent sternal wound infections and minimize postoperative complications in cardiac surgery patients during the COVID-19 pandemic. J Thorac Cardiovasc Surg. 2020;160(2):e44.

12. Allen KB, Icke KJ, Thourani VH, et al. Sternotomy closure using rigid plate fixation: a paradigm shift from wire cerclage. Ann Cardiothor Surg. 2018;7(5):611.

13. Allen KB, Thourani VH, Naka Y, et al. Randomized, multicenter trial comparing sternotomy closure with rigid plate fixation to wire cerclage. J Thorac Cardiovasc Surg. 2017;153(4):888-896.

14. Arruda MV, Braile DM, Joaquim MR, Suzuki FA, Alves RH. The use of the vancomycin paste for sternal hemostasis and mediastinitis prophylaxis. Braz J Cardiovasc Surg. 2008;23(1):35-39.

15. Losanoff JE, Jones JW, Richman BW. Primary closure of median sternotomy: techniques and principles. Cardiovasc Surg. 2002;10 (2):102-110.

16. Özdemir AC, Aykut K. Efficacy and safety of bone wax to reduce sternal bleeding following coronary bypass surgery. Ann Thor Cardiovasc Surg. 2013;20:0a-12.

17. Lazar HL, Ketchedjian A, Haime M, Karlson K, Cabral H. Topical vancomycin in combination with perioperative antibiotics and tight glycemic control helps to eliminate sternal wound infections. $J$ Thorac Cardiovasc Surg. 2014;148(3):1035-1040.

18. Jadhao M, Shah V, Raut C, Mishra P, Khandekar J, Surana K. Vancomycin local application, role in deep sternal wound infection in our experience. J Cardio-Thoracic Med. 2020;8(1):571-576.

19. Kowalewski M, Raffa GM, Szwed KA, Anisimowicz L. Meta-analysis to assess the effectiveness of topically used vancomycin in reducing sternal wound infections after cardiac surgery. $J$ Thorac Cardiovasc Surg. 2017;154(4):1320-1323.

20. Lander HL, Ejiofor JI, McGurk S, Tsuyoshi K, Shekar P, Body SC. Vancomycin paste does not reduce the incidence of deep sternal wound infection after cardiac operations. Ann Thorac Surg. 2017;103(2):497-503.

21. Desmond J, Lovering A, Harle C, Djorevic T, Millner R. Topical vancomycin applied on closure of the sternotomy wound does not prevent high levels of systemic vancomycin. Eur J Cardio-Thoracic Surg. 2003;23(5):765-770.

22. Lazar HL, Barlam T, Cabral H. The effect of topical vancomycin applied to sternotomy incisions on postoperative serum vancomycin levels. J Card Surg. 2011;26(5):461-465.

23. Vestergaard RF, Nielsen PH, Terp KA, Søballe K, Andersen G, Hasenkam JM. Effect of hemostatic material on sternal healing after cardiac surgery. Ann Thorac Surg. 2014;97(1):153-160.
International Journal of General Medicine

\section{Publish your work in this journal}

The International Journal of General Medicine is an international, peer-reviewed open-access journal that focuses on general and internal medicine, pathogenesis, epidemiology, diagnosis, monitoring and treatment protocols. The journal is characterized by the rapid reporting of reviews, original research and clinical studies across all disease areas. The manuscript management system is completely online and includes a very quick and fair peer-review system, which is all easy to use. Visit http://www.dovepress.com/ testimonials.php to read real quotes from published authors. 